\title{
Radiation myelopathy of cervical spinal cord simulating intramedullary neoplasm
}

\author{
R. FOGELHOLM, M. HALTIA, AND L. C. ANDERSSON \\ From the Department of Neurology and the II and III Departments of Pathology, \\ University of Helsinki, Finland
}

SYNOPSIS Radiation myelopathy is a well-known complication of irradiation therapy of neoplasms in the vicinity of the spinal cord. Most earlier authors have stressed the association of a normal myelogram and normal CSF protein level with this condition. One case of radiation myelopathy with a myelogram simulating intramedullary neoplasm and with extremely high CSF protein concentration is presented. Six months after myelography necropsy revealed severe atrophy of the previously thickened lower cervical spinal cord. The pathogenetic mechanisms are discussed.

Although the clinical features of radiation myelopathy are by now well documented, the differential diagnosis of intraspinal metastasis still presents difficulties. Most authors have come to the conclusion that a normal myelogram and normal protein content in cerebrospinal fluid (CSF) exclude metastasis and favour the diagnosis of a radiation lesion (Malamud et al., 1954; Itabashi et al., 1957; Dynes and Smedal, 1960; Pallis et al., 1961; Reagan et al., 1968; Coy et al., 1969; Tan and Khor, 1969; Eyster and Wilson, 1970; Burns et al., 1972; Ishida et al., 1973; Yaar et al., 1973). It has even been stated that a certain diagnosis of radiation myelopathy can be made only by negative myelography (Burns et al., 1972).

We report the clinical and pathological findings in a case of cervical myelopathy after irradiation of hypopharyngeal carcinoma with a myelogram suggesting intramedullary neoplasm associated with an extremely high CSF protein concentration.

\section{CASE REPORT}

The patient was a 57 year old woman with painful dysphagia since August 1971. In November 1971 oesophagoscopy revealed a tumour in the hypopharynx, which at biopsy proved to be a squamous cell carcinoma. The tumour was considered inoperable and the patient was given ${ }^{60} \mathrm{Co}$-therapy with a tumour dose of $6,000 \mathrm{r}$. The irradiation was given to three cervical fields, one anterior measuring $6 \times 12 \mathrm{~cm}$ with the upper border of the field at the level of C5 vertebra, and two lateral fields on each side of the neck measuring $5 \times 12 \mathrm{~cm}$ with the upper borders at the level of C3 vertebra. In order to protect the spinal cord, wedge filters were used during irradiation to the lateral fields. The treatment was given in December 1971 and January 1972 during a period of 58 days including a pause of 20 days. The spinal cord was exposed to a calculated dose of 4,000 $r$.

During treatment the symptoms improved and the size of the tumour diminished in the radiographic controls. The patient's voice became hoarse after the irradiation and painful dysphagia reappeared. These symptoms were apparently due to oedema of the laryngeal and pharyngeal mucous membranes which made tracheostomy necessary in the summer of 1972 .

In January 1973 intense pain appeared in the left shoulder radiating down the left arm to the elbow. The patient had also noticed weakening of her legs, particularly on the left side. Her right leg did not perceive hot or cold. She was admitted to the Department of Neurology one week after the beginning of these symptoms. Neurological examination revealed an incomplete Brown-Séquard syndrome with diminution of pain and thermal sensibility of the right leg and right side of the body up to the level of T8 dermatome, and slight weakness and spasticity with a positive Babinski sign in the left leg. The radiographs of the cervical spine revealed only a slight narrowing of the intervertebral discs C5/6 and C6/7. 
In March 1973 the patient was admitted to hospital in a somnolent state. She had attempted suicide with analgesics and sedatives because of intense therapyresistant pain in the left shoulder and arm. One week after this episode neurological examination revealed progression since January. The patient had a tetraparesis with left dominance and the sensibility was diminished on the right side caudal to the level of T5 dermatome. The Babinski sign was positive on both sides. Queckenstedt's test revealed a complete block and the CSF protein content was extremely high, the CSF coagulating immediately in the test tube. Three to four days after the lumbar puncture the patient's state deteriorated rapidly to near total tetraplegia. To exclude metastatic spinal cord compression gas myelography was performed. This showed thickening of the cervical spinal cord from the level of C3 vertebra down to the level of $\mathrm{T} 2 / 3$ intervertebral space with complete occlusion of the spinal canal (Fig. 1). No extramedullary expansive process was found. The swelling of the cord was thought to be a late effect of the irradiation and hence no neurosurgical therapy was performed. Instead, large amounts of corticosteroids were given to diminish

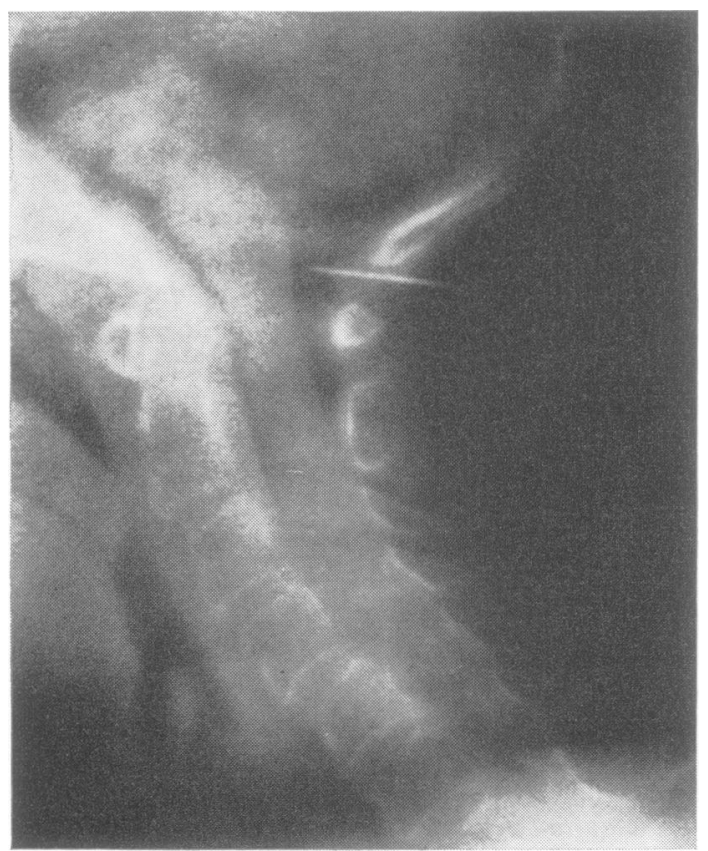

FIG. 1. Gas myelogram performed three months after onset of the symptoms of radiation myelopathy. The spinal canal is totally occluded below the level of C3 vertebra.
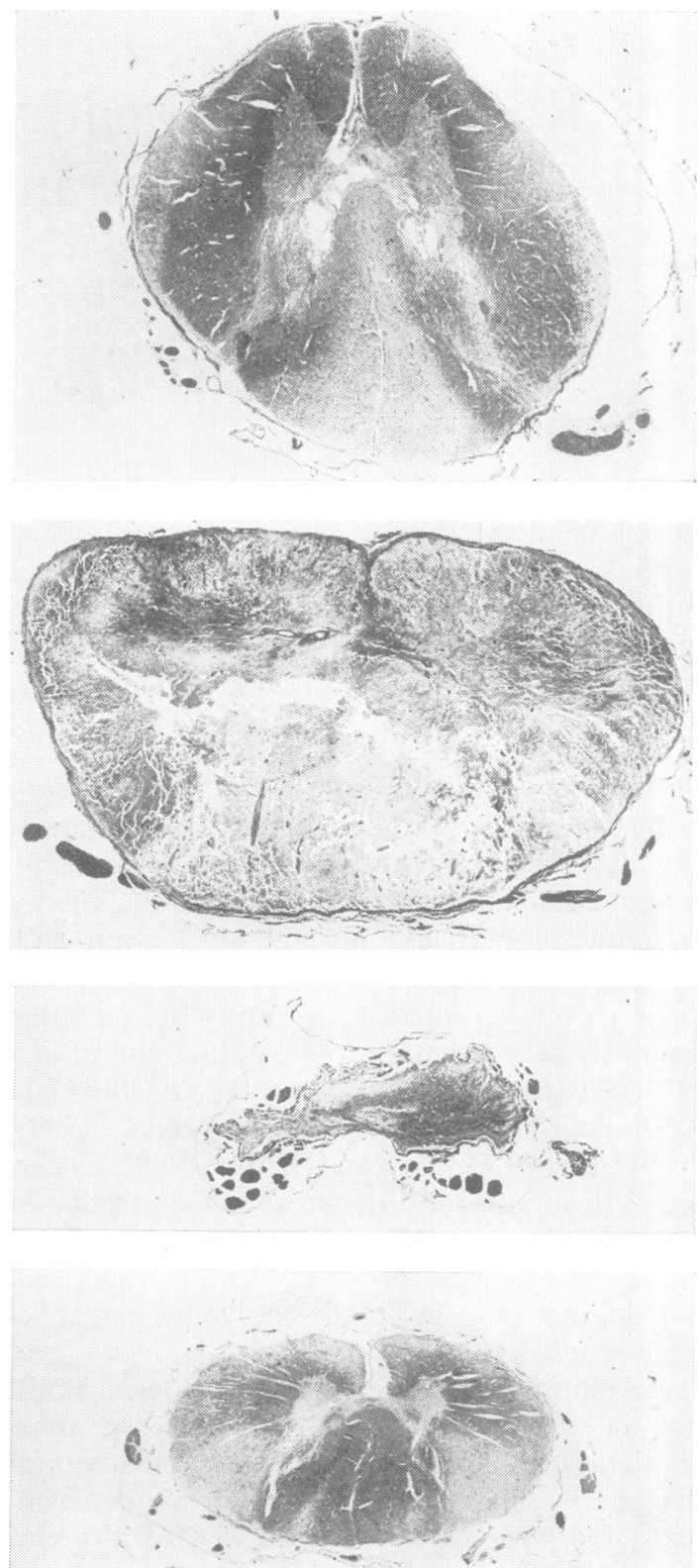

FIG. 2. (a: top) Upper part of the cervical cord. Ascending tracts are degenerated. (b) Cervical cord at the segmental level C3-C4. The cord is swollen and completely necrotic. (c) Cervical cord at the segmental levels of C5-C7. The nervous tissue has almost disappeared. The nerve roots are comparatively well preserved. (d: bottom) Upper part of the thoracic cord. The descending tracts are degenerated. All pictures at the same magnification. Stained with Luxol fast blue-cresyl violet. 
the obvious oedema of the spinal cord, but without discernible effects.

In September 1973 the patient had to be fed by intravenous infusions because of progressive dysphagia, and on 14 October she died after a period of respiratory insufficiency.

NECROPSY FINDINGS A fibrotic stricture without any evidence of tumour was found in the pharynx and hypopharynx. Histological examination revealed only scar tissue with no signs of neoplastic growth. The width of the spinal canal was normal. The bone marrow of the cervical and the upper thoracic vertebrae was displaced by scar tissue. A bilateral bronchopneumonia was considered to be the immediate cause of death.

No relevant changes were found in the brain. The cervical cord was greatly thickened at the third and fourth cervical segments. At this level the normal structure was obscured and the tissue appeared necrotic. At C5-7 segmental levels the spinal cord had almost disappeared. Only a thin strand remained, surrounded by a wrinkled and adherent meningeal sheath. No definite macroscopic changes were noted at other levels of the cord.

Histological examination of the thickened part of the cervical cord showed severe oedema and necrosis of almost the entire grey and white matter (Fig. 2b). Only a thin subpial layer appeared to be viable at places. In spite of the extensive destruction of myelin sheaths and other tissue components, only occasional lipid macrophages could be identified. The blood vessels displayed hyaline thickening of their walls with occasional thrombosis as well as a few telangiectatic distensions and small perivascular haemorrhages. In certain areas there was marked perivascular cuffing and infiltration of the blood vessel walls with degenerating mononuclear cells and a few polymorphonuclear cells intermingled with an amorphous faintly PAS-positive material. In the atrophic portion of the cord (Fig. 2c) the anterior, lateral, and posterior funiculi had almost completely disappeared with minimal glial replacement. The grey matter, though severely affected, was, however, relatively preserved and a few atrophic nerve cell bodies were seen in the anterior horns. There was severe leptomeningeal fibrosis. The spinal nerve roots, particularly the posterior ones, were comparatively well preserved. Secondary degeneration of the ascending tracts (Fig. 2a) was noted in the upper cervical cord above the swollen portion. The thoracic cord below the atrophic segment showed atrophy of the descending pathways (Fig. 2d).

\section{DISCUSSION}

The clinical picture of our case was quite typical of radiation myelopathy, corresponding to the fourth type described by Reagan et al. (1968). However, a myelogram three months after the first symptoms of myelopathy had appeared gave a picture suggesting an intramedullary tumour causing a total block of CSF circulation. The CSF protein level was extremely high. At necropsy, no neoplasm was found and the histopathological features of the cervical spinal cord corresponded to radiation myelopathy (Kristensson et al., 1967; Zeman, 1968; Burns et al., 1972). Thus, our myelographic observations seem to be in contradiction with the statements in the previous literature mentioned above.

However, Palmer (1972), Lechevalier et al. (1973), and Marty and Minckler (1973) have recently reported three further cases that came to necropsy of radiation myelopathy in which the CSF protein level was markedly elevated and myelogram showed block of the subarachnoid space due to expansion of the cord. Perusal of the literature has revealed additional cases of radiation myelopathy associated with definite swelling of the spinal cord at myelography, but without postmortem verification (Baldus, 1966; Lechevalier et al., 1973).

It seems possible that the myelographic findings depend on the timing of the examination in relation to the appearance of neurological symptoms, as well as on the extent of the radiation lesion. In our own case and in the three similar cases mentioned above myelography was performed soon (within four months) after clinical onset, and necropsy revealed severe and extensive lesions. In the cases of Palmer (1972), Lechevalier et al. (1973), and Marty and Minckler (1973) the interval between myelography and death was short (the patients died within four months from the onset of symptoms) and necropsy confirmed the myelographically observed enlargement of the irradiated spinal cord segments.

Our patient survived for a considerably longer time (nine months from the onset of symptoms and six months after the myelography). In contrast with the earlier myelographic thickening, necropsy revealed extreme atrophy of the lower cervical cord while the upper cervical segments 
were still extremely oedematous and necrotic. It therefore appears reasonable to assume that the two different types of lesion, oedema and atrophy, observed simultaneously in our case at necropsy, represent consecutive stages of a continuous process. This, as well as histopathological changes seen in the blood vessels, lends further support to the hypothesis that vascular lesions leading to increased permeability play an essential role in the pathogenesis of radiation myelopathy (cf. Kristensson et al., 1967). On the other hand, the poor reaction of glial cells to tissue destruction is not easily explained by the vascular theory alone, and suggests a more complicated pathogenetic mechanism ( $c f$. Zeman, 1968). It is of interest to note that the atrophic portion of the cervical cord corresponded to the segment exposed to the highest radiation dose owing to partial overlapping of the three fields of irradiation.

As a final conclusion, we would like to stress that radiation myelopathy need not always be associated with a normal myelogram and normal CSF protein content, which can be increased to extremely high values as a consequence of a CSF circulation block.

\section{REFERENCES}

Baldus, S. (1966). Über Spätschäden am Rückenmark nach Bestrahlung von Tumoren im Kopf- und Halsbereich. Zeitschrift für Laryngologie, Rhinologie, Otologie und ihre Grenzgebiete, 45, 123-128.

Burns, R. J., Jones, A. N., and Robertson, J. S. (1972).
Pathology of radiation myelopathy. Journal of Neurology, Neurosurgery, and Psychiatry, 35, 888-898.

Coy, P., Baker, S., and Dolman, C. L. (1969). Progressive myelopathy due to radiation. Canadian Medical Association Journal, 100, 1129-1133.

Dynes, J. B., and Smedal, M. I. (1960). Radiation myelitis. American Journal of Roentgenology, 83, 78-87.

Eyster, E. F., and Wilson, C. B. (1970). Radiation myelopathy. Journal of Neurosurgery, 32, 414-420.

Ishida, Y., Hashiba, Y., Kanda, H., Tanaka, T., and Niibe, H. (1973). An autopsy case of radiation myelopathy. Acta Pathologica Japonica, 23, 385-395.

Itabashi, H. H., Bebin, J., and DeJong, R. N. (1957). Postirradiation cervical myelopathy. Report of two cases. Neurology (Minneap.), 7, 844-852.

Kristensson, K., Molin, B., and Sourander, P. (1967). Delayed radiation lesions of the human spinal cord. Report of five cases. Acta Neuropathologica, 9, 34-44.

Lechevalier, B., Humeau, F., and Houtteville, J. P. (1973). Myélopathies radiothérapiques 'hypertrophiantes'. A propos de cinq observations dont une anatomo-clinique. Revue Neurologique, 129, 119-132.

Malamud, N., Boldrey, E. B., Welch, W. K., and Fadell, E. J. (1954). Necrosis of brain and spinal cord following X-ray therapy. Journal of Neurosurgery, 11, 353-362.

Marty, R., and Minckler, D. S. (1973). Radiation myelitis simulating tumor. Archives of Neurology, 29, 352-354.

Pallis, C. A., Louis, S., and Morgan, R. L. (1961). Radiation myelopathy. Brain, 84, 460-479.

Palmer, J. J. (1972). Radiation myelopathy. Brain, 95, 109122.

Reagan, T. J., Thomas, J. E., and Colby, M. Y., Jr (1968). Chronic progressive radiation myelopathy. Its clinical aspects and differential diagnosis. Journal of American Medical Association, 203, 106-110.

Tan, B. C., and Khor, T. H. (1969). Radiation myelitis in carcinoma of the nasopharynx. Clinical Radiology, 20, 329331.

Yaar, I., Herishanu, Y., and Lavy, S. (1973). Radiation myelopathy. European Neurology, 10, 83-88.

Zeman, W. (1968). The effects of atomic radiations. In Pathology of the Nervous System. vol. 1, pp. 864-939. Edited by J. Minckler. McGraw-Hill: New York. 